\title{
Research on Preschool Justice in Rawls Principles - A Case of Pre-School Three-Year Action Plan in Shaanxi and Gansu Li Feng ${ }^{1, a_{*}}$ \\ ${ }^{1}$ Yulin University, Yulin, Shannxi, China, 719000 \\ ${ }^{a *}$ email
}

Keywords: Difference Compensation, Rawls, Preschool Policy, Justice Principles

\begin{abstract}
Preschool equity issues is the focus of the Balanced Development of Preschool Education in the "Outline" and "Opinion" in the guidance, driven by pre-school three-year action plan of the provinces of China has made great achievements and promoted the remarkable development of preschool education. Formulation and implementation of the contents of pre-school three-year action program policies and basic principles of justice Rawls connotation has fit between that guarantees each individual affected by pre-school education opportunities for freedom and equality, so that the "most disadvantaged persons" through compensation obtain substantial justice and equality. "Three-year action plan" of the urgent need to improve pre-school, pre-school education through the national real fair in terms of financial and other resources in the western region and "differential compensation", the realization of China.
\end{abstract}

\section{Introduction}

The importance of the development of preschool education has been gradually recognized and accepted as a modern society, as one of the government's responsibility, China has successively promulgated the "Long-term Education Reform and Development Plan (2010-2020)" and "the State Council on the current preschool education the number of opinions "under this Directive, provinces and cities have introduced three-year action plan for local and gradual implementation. They highlighted the public welfare and Pratt \& Whitney adhere to pre-school education, so as to protect the equal rights of all citizens affected by pre-school education. However, due to China's economic development gap between East and West, urban and regional development, serious imbalance, pre-school education resources cannot meet the needs of society, so fair question preschool education remains the center of gravity of the balanced development of preschool education in three provinces policy action plan also reflected the need to give pre-school policy development inspired by the more advanced and perfect theory.

Equity theory in the 1970s the famous American philosopher John Rawls • (John Rawls) published "A Theory of Justice", is regarded as one of World War II Western political and moral philosophy of the most important works are also less recognized. He believes that social inequalities seriously restricted the development prospects of life and most people and because of differences in inequality between individuals or class background and other factors caused by natural ability is not just the main distribution system of social justice as the basic goodness topics examined.

\section{The Three-Year Plan Action Policy is Uniform with Basic Connotation Logic of Rawls's Justice Principles}

The Three-Year Action Plan Policies Reflect the State Wishes to Achieve Pre-Fair. Rawls, where social justice is more important than individual justice, social justice is the equitable distribution of social rights and interests, he proposed the principle of justice as fairness from the perspective of social justice, that "for a society, its social system substantially affect the scope of its members to choose, and even affect the character of its members on the plastic. in turn, the social system through individual behavior to create, maintain, and change. "The principles of justice 
Rawls It is the cornerstone of the country's political system. "Long-term Education Reform and Development Plan (2010-2020)" also clearly stated, "to promote fair as a national basic education policy," he pointed out: "Educational equity is an important foundation for social justice Fair Education is the key to opportunity. fair, the basic requirement is to protect the citizens enjoy the right to education according to the law, the focus is to promote the balanced development of compulsory education and support disadvantaged groups, fundamental measure is the rational allocation of educational resources to rural areas, remote and poor areas and ethnic minority areas to accelerate closing the education gap the main responsibility for education fair in the government, the whole society should work together to promote fairness in education. "The most basic pre-school stage as an individual development and learning phase, was once restricted China's economic development, industrialization into the morass, not only We did not get enough attention, and the prevalence of such pre-utilitarianism and inner-city preschool education gap between urban and rural areas is widening. 2010 starting provinces to develop three-year action plan reflects the national policy for the development of pre-school and pre-school education to achieve a fair aspirations and actions. In the "Outline" to guide the formulation and implementation of the objectives of our policy of pre-school education are as much as possible to protect the rights of each member country to education, so as to enhance citizens' basic qualities.

The Development of Pre-School Education Policy Make Efforts to Protect Children's Right of Education Under Different Economic Conditions."The so-called 'fair', its true significance lies in 'equality'." Rawls' theory of justice includes two principles, three levels. The first principle: everyone has all of the most extensive system of equal basic liberties compatible with a similar liberty and the system should have an equal right. The second principle: social and economic inequalities arrangements should enable them to: (1) In line with the principles of justice storage case is suitable for the best interests of the least beneficiaries; (2) the fair equality of opportunity under conditions in which is open to all people of all duties and status. Simply the principles of the three successive priorities - the principles of equality and freedom, equal opportunity, the difference principle.

The second principle applies to social and economic development is not balanced state of reality. In our pre-school guidance document "views", it requires governments at all levels to provide "wide coverage, covers basic" pre-school public service. Increase government investment, new construction, renovation, expansion safety for of a number of kindergartens. Three-year action plan provinces are regulated by government departments to enable school-age children in the region to enjoy an equal right to education to achieve. For example, three-year action plan policies in Shaanxi Province and Gansu Province are to improve the development of the province's kindergarten coverage on the basis of the province over the existing nursery development, and actively establish and organize inclusive kindergarten, ensures that most school-age children can be close admission to improve pre-school gross enrollment rate. This development plan is a pre-school in the different regions of the province of equality of children's right to education that is guaranteed regardless of age children born in urban or rural, mountainous or pastoral, including children with disabilities have the opportunity to contact or at least receive a partial or complete pre-school education this pre-school education to the development of the country, especially in less developed western regions of children, it is a strong guarantee universal access to pre-school education fundamental rights. Especially the rights of Shaanxi Province in the proposed three-year action plan to achieve one year of free pre-school policy, it is at the forefront of the national pre-school development, what really makes rural children into kindergarten supported economy.

Make Efforts to Guarantee Equality in Nature by Increasing the Quantity and Quality of Preschool Professional Teachers. Rawls believes came from individual social status is unfair, the class of people, different family environment and natural talent, luck also acquired contingencies These are objective facts, so that it reaches over the entire state of social justice, it is necessary after "Mu ignorance" of the people to choose two principles of justice, so as to limit inequality caused due to various contingencies in the regulation of the difference principle. "Difference principle requires that, no matter how great the difference between wealth and income, and no matter how 
reluctant people to work for themselves in the product earned the largest share, memory inequalities must indeed effectively serve the interests of the most disadvantaged Otherwise this inequality is not allowed. "It is an essential difference between the principle of reciprocity principle, social cooperation possible, whether it is more favorable position for the person or for the less favorable position seems people can acceptable, because in the "ignorance Mu" after that, no one will know their future position in society, everyone must let the principle guarantees of future weakest individuals enjoy equal access to adequate protection to life through differences, let the difference principle form of liberal equality into substantive equality. The basic structure of society and the system should be guided by the principles of justice in the construction, in order to pay more attention to the reality of inequality, and thus regulate this inequality.

The maximum inequality western rural pre-school education is under pre-utilitarian guiding ideology too will focus on the advantages of resources to the cities, concentrated in the nursery, where a few, while the majority of children of school age children in rural and urban migrants even if there is admission conditions, cannot receive the same quality of teaching. Preschool Teaching Quality the main force in the professional teachers. From the three-year action plan content Shaanxi and Gansu provinces can be found in pre-professional teachers to enhance the quantity and quality of teaching is to protect the rural pre-school education an important part of the fair. National training program through three training network provincial, city and county, to a large number of counties did not enter kindergarten teachers prepared to free training, the province's efforts to protect children receiving comparable quality preschool teachers guide, geographical restrictions caused by the talent or not reduce the degree of equality.

\section{Rawls' Justice Principles Provide a Theoretical Direction for Improving Pre-School Three-Year Action Plan}

Rawls' difference is not proposed to highlight the differences, but stressed that embodies a kind of minimal given equal beneficiaries. That is the state of society as a whole is a collaborative possible to achieve substantive equality. In fact, his difference principle is the principle of compensation. He said: "The principle of compensation is considered, in order to treat everyone equally, to provide real equality of opportunities, society must pay more attention to those less gifted and people born in less favorable social status of this concept is according to equality. "With the fact that a formal alternative to inequality in inequality, thus achieving real equality, its essence lies in the demands of all the basic social rights, such as distribution requirements Jin Liping various interests and social responsibility co-produced.

By extension, pre-school children in the justice means first of all, whether under geographical or economic conditions in the pre-school education by the equal rights and obligations. Secondly, within the scope of education, quality of education should achieve equality of opportunity, and even more the lack of economic development or physical defect child should receive a higher quality education. Because the starting point for the unequal state authorities should implement the principle of justice in the distribution of opportunities in the most disadvantaged in society to make preferential policies to compensate. This compensation is not a requirement for all policies, such as rural children should be equivalent to the absolute, which is not feasible in the "Great State Office poor education," the reality, but to recognize the difference but in the basis to ensure that each a pre-school children in equal freedom rights and obligations to achieve equality of opportunity in access to educational content and resources, combined with the principles of social justice vulnerable compensate, through public policies, in ensuring the development of education of disadvantaged children to achieve fairness and justice on equality. Even in economically developed countries such as the United States practice of equality, making education the time, also take decades to bear fruit. How to achieve fairness and justice preschool and thus achieve human development and equity and justice, the policy of pre-school education should be improved. Therefore, we need continuous feedback during execution of new issues in order to promote the progress of improvement and development of pre-school education policy. 


\section{Learn the Rawls Justice Principles Thinking and Improve the Policies and Practices of Three-Year Action Plan}

Rawls's principles of justice from the "veil of ignorance" hypothesis, more inclined to make education policy provisions sense of ethics, so his theory at the same time is also much acclaimed controversy and criticism, but his theory of value orientation of pre-school education policy opens a door to ponder.

Combined with a Variety of Compensation to Achieve Coexistence of Diverse Balance. Three-year action plan provided by the national and provincial special funds to invest in the construction or renovation and expansion of the kindergarten, in the western rural town centers to improve the number of kindergarten, but we also see that, because the policy will stress the town center nursery building, making the county, township government compliance inspection will focus money and resources on a small number of teachers in kindergarten, in practice expanded imbalance western rural kindergarten. At the same time, because of geographical characteristics, the gap between the western, relatively large village and village, township government usually located in an administrative village, other villages and distant with its distance, in this case, from the town center at the kindergarten unable action to benefit the entire rural school-age children.

Compensation policies for rural pre-school education should be based on reality, according to local conditions, in order to township primary school as the center of expansion kindergarten. In the case of kindergarten-age children enough to accommodate the situation, try to learn from the experiences and lessons of compulsory education, for example, of Shandong province in the pilot stage of compulsory education, "education voucher" policy. By giving school-age children can be converted into paid government subsidies for kindergarten only "special ticket" voucher children choose the nearest public or private kindergarten, in this way not only to compensate rural children have greater access to pre-school education the right to choose and to be compensated private preschool, its cost-sharing, change the status quo only government-funded public education, to promote public and private kindergartens by way of the development of fair competition, thereby increasing the enrollment rate of pre-school children.

At the same time, we must promote the diversification of trainees and parents will be included in pre-school training objects. By promoting pre-school three-year action plan to give parents the western rural areas also realize what is efficient family education for parents to provide the appropriate guidance, prompting parents to shift the center of superstition and let go to kindergarten exemption and other misconceptions. You can also identify the effectiveness of the policy by the parents.

Implement Standardized and Performance Accountability and Turn Attention from Financial Compensation to the Education Quality. Three-year action plan policy cannot solve the preschool gap between the provinces. Provinces to local conditions themselves are widening the gap between regions, while Shaanxi Province has been achieved when the free pre-school year, pre-school education in Gansu Province is because a weak foundation, lack of economic development in order to improve the pre-school enrollment rate of one to three years and efforts. Of course, we cannot unworthy and leaving pre-school because of regional differences has developed stagnation, lack of development and progress in waiting areas. Compensation Rawls not only compensate for the negative economic level, we have to admit that imbalance between regions and between different geographical regions with the development of pre-school education on the basis of the positive recognition, to encourage their own provinces It based on capacity development, by increasing the western rural areas and ethnic minority areas in the quantity and quality of pre-school education to achieve develop diverse ways to achieve equality of outcome.

Refine Rules and Oversight Mechanisms, Guarantee Pre-School Education Resources and Substantive Equality of Opportunities. Preschool balanced development need to "compensate for the difference," Rawls is to emphasize all aspects of distributive justice from the height of the whole society. In terms of education policy, he proposed "In order to treat everyone equally, to provide real equal opportunity, society must pay more attention to those born in the lower talent and less favorable social status of people. Follow this principle and the more large resources may be spent 
on poor intelligence, rather than the higher people who, at least at some stage, for example, during the early school education. The difference principle to change the target of the basic structure of society, so that the whole structure of the system a purpose no longer emphasizes social efficiency and technocratic values, although not equivalent to the principle of compensation, but to achieve the principle of compensation. "This is a national problem, and it is a national responsibility.

Even in economically developed countries such as the United States, during the education fair practice time take decades to bear fruit. Therefore, we need continuous feedback during execution of new issues in order to promote and improve the practice of pre-school education of pre-school education policy development and progress.

\section{Acknowledgements}

Fund Project: Shaanxi Provincial Department of Education Research Project (No. 13JK0305).

\section{References}

[1] Tao mousse Borg, Gu Su, Liu Xuemei translated: "Rawls: The Life and Theory of Justice", China Renmin University Press, 2010 edition, page 30.

[2] Long-term Education Reform and Development Plan (2010-2020) [DB / OL]. http: / / www. gov. cn / jrzg / 2010-07 / 29 / content_1667143. htm.

[3] Aristotle: "Politics", Wu Shou Peng translation, Commercial Press, 1997 edition, page 153.

[4] John Rawls: "justice as fairness - New Theory of Justice," Yao Dazhi translation, Shanghai Joint Publishing, 2002 edition, p. 103.

[5] John Rawls: "Theory of Justice", Huaihong, Baogang, Liao Shenbai translation, China Social Sciences Press, 1998 edition, page 100.

[6] John Rawls, Huaihong translated: "Theory of Justice", China Social Sciences Press, 1988 edition, p. 101.

[7] John Rawls, Huaihong translated: "Theory of Justice", China Social Sciences Press, 1988 edition, p. 102. 